\title{
In vitro antimicrobicidal and cytotoxicity efficacy of gold nanoparticles synthesized from Alternaria brassicae (KF934409)
}

\author{
Faria Fatima ${ }^{1 *}$, Neelam Pathak ${ }^{2}$, Smita Rastogi Verma ${ }^{3}$ and Preeti Bajpai ${ }^{2}$ \\ ${ }^{1}$ Integral Institute of Agricultural Science and Technology, Integral University, Lucknow-226026, India \\ ${ }^{2}$ Department of Biosciences, Integral University, Lucknow-226026, India \\ ${ }^{3}$ Department of Biotechnology, Delhi Technological University, Delhi-110042
}

Received: October 4, 2016; Accepted: October 24, 2016; Published: November 4, 2016

*Corresponding author: Faria Fatima, Integral Institute of Agricultural Science and Technology, Integral University, Lucknow-226026, India, E-mail: fatimafaria45@gmail.com

\begin{abstract}
Nanotechnology is emerging as one of the most revolutionizing area in research field. Biological methods of reduction of metal ions are often preferred because they are non-toxic, safe, clean, biocompatible and environmentally acceptable. Alternaria brassicae was isolated from rhizospheric region and used for the extracellular synthesis of gold nanoparticles (AuNPs). Further, the study was performed to estimate the antibacterial, antifungal and cytotoxic efficacy of AuNPs. The immunomodulatory efficacy of AuNPs was investigated on various pathogenic microorganisms and human macrophages cell lines (THP1- $\alpha$ ). Stable AuNPs were produced when an aqueous solution of chloroauric acid (HAuCl4) was reduced by fungal biomass. Production of nanoparticles was confirmed by the color change from yellow to pinkish violet after approximately $72 \mathrm{hr}$ of reaction. The produced nanoparticles were then characterized by UV-vis spectroscopy, DLS and Transmission electron microscopic analyses. The TEM images of sample revealed that the AuNPs were spherical and hexagonal in shape. Biosynthesized AuNPs were ranged in size from $\sim 15-72 \mathrm{~nm}$. These AuNPs were also assessed for their antimicrobial and cytotoxic efficacy. The results indicated towards efficient antimicrobial activity of AuNPs against Enterobacter aerogene, Bacillus cereus and Trichoderma sp. at higher concentrations. Cytotoxicity analysis of AuNPs on THP1 $\alpha$ cell lines revealed dose dependent behavior. In conclusion, this study proposed the inimitable character of AuNPs prepared from A. brassicae. AuNPs synthesized by this fungus can be either used as cost effective antimicrobial, insecticidal agents or nontoxic immunomodulatory delivery vehicle.
\end{abstract}

Keywords: Alternaria brassicae; Antimicrobial; Cytotoxicity; Gold Nanoparticle

\footnotetext{
Abbreviations

AuNPs: gold nanoparticles; DCFH-DA: 2,7-dichlorofluorescin diacetate; DMSO: dimethyl sulfoxide; ITS: Inter transcribed spacer; MTT: 3-(4,5-dimethylthiazol-2-yl)-2,5-diphenyltetrazolium bromide; OD: Optical density; SI: Solubilization Index; SEM: Scanning electron microscopy; TEM: Transmission electron microscopy; UV-Ultraviolet-Visible.
}

\section{Introduction}

Nanotechnological study mainly focuses on the advancement of man-made as well as natural systems for the synthesis of materials at nanoscale level [1]. In recent years, metal nanoparticles have been the subject of interest due to their unique chemical, physical and optical properties [2]. These nanomaterials have a widespread range of implications not only from catalysis to agriculture but also from electronics to biomedicine which is due to their small dimension and large surface area. It was reported that the easiest method for the synthesis of nanoparticles is the reduction of their respective salts [4] (S-1). Nanoparticles can be synthesized from physical, chemical and biological methods. Physical and chemical methods like sonochemical processing, cavitation processing, UV irradiation and high energy ball-milling proved as an expensive, toxic and involve the use of harmful chemicals. Hence, in order to produce the nanoparticles by safe, secure, biocompatible eco-friendly methods, many biological systems have been used to produce the nanoparticles [5]. Some well known examples include the use of bacteria, fungi and plants for their production. Accumulation of metal ions by microbes has been regarded as lowcost, environment-friendly and easily achievable phenomenon. However, fungi, in particular, are a favored choice for the synthesis of different nanoparticles due to their high tolerance towards metals, high wall-binding capacity, can be easily scaled up, ability to secrete large amount of enzymes [6] and due to their capability of accumulating metals by physicochemical and biological mechanisms. The fungal supernatants were used for synthesis of different types of nanoparticles [7, 8]. Scientist used Fusarium oxysporum for both intracellular and extracellular production of gold nanoparticles [3, 9]. The rapid reduction of metal ions resulting in the formation of stable gold nanoparticles of variable sizes and shapes was reported [26]. It was reported that cell-free filtrate containing NADPH-dependent enzyme of Epicoccum nigrum, when react with the aqueous chloroauric acid solution, it has the ability to synthesize gold nanoparticles 
at ambient temperature [25]. However, AuNPs production by Alternaria brassicae was not reported yet. The present investigation is an effort to synthesize gold nanoparticles from A. brassicae (GenBank: KF934409), a phosphate solubilizing fungus, isolated from rhizospheric region of leguminous plant from Central Institute of Medicinal and Aromatic Plants (CIMAP) lawn $\left(29^{\circ} \mathrm{N} 79.38,243.84 \mathrm{MSL}\right)$. The potential antimicrobial and cytotoxic activity of these myco-nanoparticles synthesized has been evaluated.

\section{Material and methods}

\section{Isolation, screening and characterization of $A$ brassicae (KF934409)}

The fungus was isolated from soil of vegetative region near Central Institute of Medicinal and Aromatic Plants (CIMAP) lawn (29 o N 79.38, 243.84 MSL). Lucknow, India and screened by its phosphate solubilizing efficiency on Pikovskaya's medium by plate assay [15]. The fungal colonies were subculture on fresh potato dextrose agar (PDA) media and the plates were further incubated in inverted position for $72 \mathrm{hr}$ at $28 \pm 4^{\circ}$ C for halo formation around the fungal colony. Further the biochemical characterization of the fungus was tested on the basis of colony morphology, conidial microscopic analysis, and phosphate solubilization index (SI), starch and cellulose hydrolysis test according to standard protocols [16]. However, the molecular characterization of fungus was done by using 18S rRNA sequencing. Genomic DNA of selected fungus was isolated and subjected to high-fidelity PCR using universal primers i.e., forward primer (5'-GGAAGTAAAAGTCGTAACAAGG-3') and reverse primer (5'-TCCTCCGCTTATTGATATGC-3') and examined on 1.5 $\%$ agarose gel. The PCR product was sequenced bi-directionally via the forward and reverse primers. Homology was detected by BLASTN sequence match between this 18S rDNA sequence and the strains accessible at the public databases (Genbank, European Molecular Biology Laboratory (EMBL) and DNA Data Bank of Japan (DDBJ) followed by perform hierarchical cluster analysis by using the UPGMA (Unweighted Pair Group Mathematical Average) algorithm [17]. The sequences were further aligned by means of CLUSTALW2 program and its molecular and phylogenetic evolutionary analysis was performed. The nucleotide sequences of $18 \mathrm{~S}$ rRNA gene segments determined in the present study have been submitted in GenBank database under accession number KF934409.

\section{Biomass preparation and extracellular biosynthesis of gold nanoparticles}

MGYP (Maltose, Glucose, Yeast and Peptone) broth comprising of malt extract $(0.5 \%)$, glucose $(1 \%)$, yeast extract $(0.3 \%)$ and peptone $(0.5 \%)$ was used for the growth of fungus aerobically. The culture was incubated at $28^{\circ} \mathrm{C}$ and harvested after $120 \mathrm{hr}$ of growth by sieving through a plastic sieve followed by washing with sterile double-distilled water. Initially, $20 \mathrm{~g}$ of biomass (wet weight) was transferred to $100 \mathrm{ml}$ deionized water for $48 \mathrm{hr}$ at $28^{\circ}$ $\mathrm{C}$ in an Erlenmeyer flask and agitated at $120 \mathrm{rpm}$ for the release of secretory proteins. $1 \mathrm{mM}$ of gold tetra hydrate was added to the Erlenmeyer flasks and the reaction was allowed to proceed under dark conditions for synthesis of AuNPs. Time-dependent formation of AuNPs was observed by using ultraviolet-visible spectrophotometer (Beckman DU-20 spectrophotometer). The scanning range was $400-800 \mathrm{~nm}$ for AuNPs at a scan speed of 420 $\mathrm{nm} / \mathrm{min}$. The data was performed using "UVWinlab" software.

\section{Characterization of gold Nanoparticles}

Differential light scattering (DLS): AuNPs suspensions were prepared in distilled water $\left(\mathrm{dH}_{2} \mathrm{O}\right)$ by using a bath-sonicator (ULTRAsonik 57 X, 50/60 Hz, California, USA) for measurements of nanoparticles size. Viscosity measurements were performed on $\mathrm{dH}_{2} \mathrm{O}$ with the help of a Viscometer SV-10 (A\&D Instruments Ltd., UK) at 25ㅇ $\mathrm{C}$ and the recorded values were used in all DLS size estimations. The viscosity of $\mathrm{dH}_{2} \mathrm{O}$ at $25^{\circ} \mathrm{C}$ was 0.887 centipoise. DLS size measurements were performed with the aid of a Malvern Zeta Sizer Nano ZS (Malvern Instruments, Worcestershire, UK) working at version 5.03 of the systems Dispersion Technology Software (DTS Nano). The samples for DLS were equilibrated at $25^{\circ} \mathrm{C}$ for $3 \mathrm{~min}$ before each measurement. The refractive index (RI) of AuNP.dH $\mathrm{H}_{2} \mathrm{O}$ was 1.430 .

Transmission electron microscopy (TEM): For TEM analysis, the synthesized AuNPs were prepared by placing a drop of synthesized nanoparticles over gold coated negative grid followed by evaporation of the solvent [18]. TEM analysis was performed on Perkin-Elmer model, which was operated at an accelerating voltage of $1000 \mathrm{kV}$ (JEOL, JEM-1000).

Antibacterial efficacy: Pseudomonas sp, Enterococcus faecalis, Klebsiella pneumonia, Escherichia coli, and Sterptococcus pyogenes were procured from National Chemical Laboratory (NCL), Pune followed by their sub culturing on nutrient broth media at $37^{\circ} \mathrm{C}$. The turbidity (OD600) was sustained at 0.8 corresponding to $\sim 1 \times 10^{8} \mathrm{CFU} / \mathrm{ml}$. Agar well diffusion assay was used to analyze the antibacterial efficiency of synthesized AuNPs [19] where $1 \mathrm{ml}$ of each bacterial culture was placed on Muller Hinton agar medium (beef extract $2 \mathrm{gm} / \mathrm{l}$; casein acid hydrolysate $17.5 \mathrm{~g} / \mathrm{l}$; starch $1.5 \mathrm{~g} / \mathrm{l}$; agar $17.0 \mathrm{~g} / \mathrm{l}$ ). $5 \mathrm{~mm}$ diameter wells were prepared and filled with a range of concentrations of AuNPs $(15 \mu \mathrm{M}, 75 \mu \mathrm{M}, 150 \mu \mathrm{M}, 250 \mu \mathrm{M})$. Antibiotic tetracycline at a concentration of $25 \mu \mathrm{g} / \mathrm{ml}$ was used as control (Ab). Further potential of AuNPs at a concentration of $200 \mu \mathrm{M}$ was analyzed along with $25 \mu \mathrm{g} / \mathrm{ml}$ antibiotic tetracycline (Ab + AuNPs). Plates were incubated overnight at $37^{\circ} \mathrm{C}$ for overnight. All experiment was carried out in triplicate and the average zone of inhibition, excluding the diameter of well, was recorded for each bacterial species in centimeters.

Antifungal efficacy: The antifungal activity of AuNPs was tested against Aspergillus fumigatus and Penicillium marneffei by agar well diffusion method [20]. Aliquot of $50 \mu \mathrm{l}$ spores suspension $\left(\sim 1 \times 10^{8}\right.$ spores $\left./ \mathrm{ml}\right)$ of each isolate was streaked in radial patterns on the surface of PDA media plates (per liter: sliced washed unpeeled potatoes $200 \mathrm{~g}$; dextrose $20 \mathrm{~g}$; agar $20 \mathrm{~g}$ ). Further, $5 \mathrm{~mm}$ of agar wells in diameter were prepared and filled with a range of concentrations $(100 \mu \mathrm{M}, 150 \mu \mathrm{M}$ and $200 \mu \mathrm{M})$ of AuNPs. Further potential of AuNPs at a concentration of $200 \mu \mathrm{M}$ was analyzed along with $25 \mu \mathrm{g} / \mathrm{ml}$ antibiotic Amphotericin B (Ab 
+ AuNPs). The cultured plates were incubated at $28^{\circ} \mathrm{C} \pm 4^{\circ} \mathrm{C}$ for 7 days. The average inhibition zone, excluding well, for each case was measured in centimeters.

Maintenance of cell lines: THP1 $\alpha$ (Human macrophage cell line) was obtained from the National Center of Cell Sciences, Pune, India and further preserved at Animal Tissue Culture facility of Central Drug Research Institute (CDRI). Dulbecco's modified Eagle's medium (DMEM) supplemented with $10 \%$ Foetal calf serum (FCS) and $1 \%$ antibiotic-antimycotic solution was used for cell culture maintenance at $37^{\circ} \mathrm{C}$ and $5 \% \mathrm{CO}_{2}$ using standard cell culture methods.

Cytotoxicity assay: In order to analyze the cell viability of human macrophages cell lines (THP1 $\alpha$ ) was used. It was determined by MTT [3-(4, 5-dimethylthiazol-2-yl)2,5-diphenyltetrazolium bromide] conversion assay [21]. 1 x $10^{6}$ cells $/ \mathrm{ml}$ were plated in 96 -well culture plates and incubated with rising concentrations of nanoparticles $(10 \mu \mathrm{M}, 25 \mu \mathrm{M}, 50 \mu \mathrm{M}, 100$ $\mu \mathrm{M}, 150 \mu \mathrm{M}$ and $200 \mu \mathrm{M}$ ) for $24 \mathrm{hr}$ at $37^{\circ} \mathrm{C}$ in $\mathrm{CO}_{2}$ incubator. The MTT dye was further added to each well and plate was incubated at $37^{\circ} \mathrm{C}$ for $4 \mathrm{hr}$. The absorbance of insoluble formazan salts was evaluated at $550 \mathrm{~nm}$ using spectrophotometer "Powerwave XS "BIOTEK, USA" [22]. Data analyzed were used to plot a dose-dependent reaction curve and the metal nanoparticles concentration required to kill $50 \%$ of cell population $\left(\mathrm{IC}_{50}\right)$ was determined.

\section{Cell viability $(\%)=$ Mean OD $\times 100 /$ Control OD}

Statistical analysis: All the experiments were performed in triplicates and results were expressed as mean $\pm \mathrm{SD}$. Oneway analysis of variance (ANOVA) with a Dunnett's test was performed for the multiple comparisons for normally distributed samples with homogenous variance. Statistically significant differences were set at $\mathrm{p}<0.05$.

\section{Results and discussion}

\section{Synthesis of fungal AuNPs}

Alternaria brassicae, secretes numerous enzymes like nitrate reductases, lignin peroxidase, laccase and phosphatase whose potential have been checked in various fields of industrial, pharmaceuticals and commercial purposes [23]. Fungi have been reported a better nanoparticles producers because of their toxicity reception, bioaccumulation, simple downstream processing, comparatively economic in comparison with others, and easy biomass handling [24]. Considering this fact AuNPs were synthesized from fungus A. brassicae where the supernatant of fungus was used as reducing and stabilizing agent for $1 \mathrm{mM}$ of gold tetrahydrate salt. The appearance of a pink color in solution gave the clear indication of the formation of AuNPs (Figure 1). Reduction of gold ions was reflected in the color of the solution, which varied from pale-yellow to pink. One $\mathrm{mM} \mathrm{HAuCl}_{4}$, used as control, when subjected to similar conditions did not demonstrate any color change.

Characterization by spectrophotometric, DLS and Transmission electron microscopic analyses (TEM)

No indication of absorption in the range of $400-800 \mathrm{~nm}$ for the fungal extract was shown by UV-vis spectrophotometer while the fungal extract when exposed to $\mathrm{HAuCl}_{4}$ showed a distinct absorption at around $540 \mathrm{~nm}$ (Figure 2a). Such type of peak is in accordance with the earlier report on metal nanoparticles which ranged between 10-100 nm [10]. DLS spectra showed an intensity of $79.82 \mathrm{~nm}$ for AuNPs (Figure 2b). This technique enables the particle size determination by measuring the changes in the light intensity scattered from a suspension or solution. TEM micrographs of AuNPs depicted two different forms viz., spherical and hexagonal formed. This was further confirmed by the representative images recorded from the drop-coated film of the gold nanoparticles uniformly dispersed on grid. The size of the AuNPs ranged from $72 \mathrm{~nm}$ (hexagonal), $28 \mathrm{~nm}$ and $15 \mathrm{~nm}$ (spherical), respectively (Figure 3). The size variation is due to oxidation of metal salts into their relevant nanoparticles in the presence of reductase enzymes

\section{Antibacterial activity}

The bactericidal activity of AuNPs were studied using the pathogenic strains of bacteria, namely E. faecalis, E. coli, K. pneumonia, Pseudomonas sp., S. pyogenes using agar well diffusion method. The results recorded in centimeters for

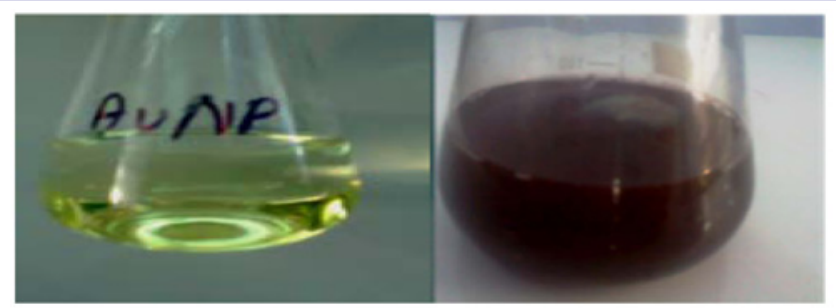

Figure 1: Nanoparticles formation on the basis of colour change due to surface Plasmon

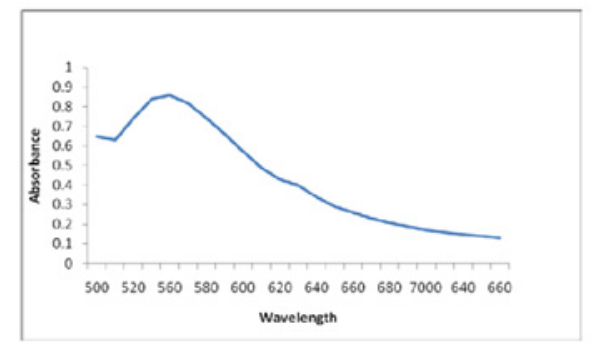

(a)

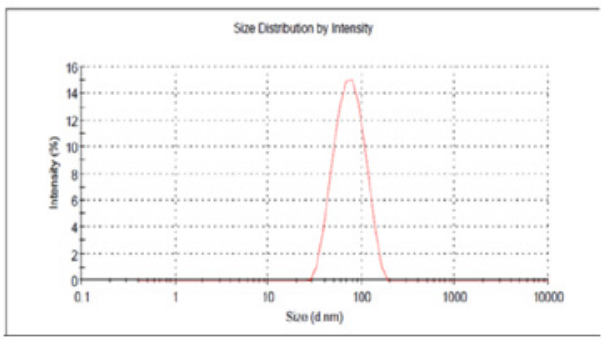

(b)

Figure 2: (a) UV-VIS spectrophotometry of AuNPs (b) DLS spectrum of AuNPs 
AuNPs are shown in Figure 4. The comparative histogram demonstrated that the best antibacterial efficacy of AuNPs was against Pseudomonas sp. and E. coli, followed by K. pneumonia. Marked increase in antibacterial activity was demonstrated with increasing concentration of AuNPs. In addition, the efficacy of AuNPs was found to be enhanced in combination with the antibiotic tetracycline rather than alone.

Nano-gold is an effective and a fast-acting microbicide against a various pathogenic bacteria and fungi that have been utilized in various fields like in the industrial, medical field [11]. In the present study, somewhat similar results were also obtained where gold nanoparticles exerted antibacterial activities along with the standard antibiotic (tetracycline) against Pseudomonas $s p$. and E. coli. It is reported that AuNPs reacting with sulfur containing proteins in the cell interior as well as compounds containing phosphorous such as DNA will affect the cell division and respiratory chain in bacteria, ultimately causing the cell death [12].

\section{Antifungal activity of AuNPs}

The colloidal AuNPs inhibited the growth of the fungus $(A$ fumigates and P. marneffei) which was seeded in the Muller Hinton agar plate forming a zone of inhibition around the central cavity. The zone of inhibition with diameter of $1.3 \mathrm{~cm}$ was recorded in case of A. fumigates and $1.5 \mathrm{~cm}$ in P. marneffei (Figure. 5). The antifungal activity is due to the disruption of membrane bound enzymes and lipids or formation of insoluble compounds by inactivation of sulfhydryl groups in the fungal cell wall which causes cell lysis [13].

\section{In vitro cytotoxicity assay}

The effect of gold nanoparticles on the cell viability of THP1 $\alpha$ (human macrophage cell lines) was assessed by MTT assay. Various concentrations of gold nanoparticles for cells treatment $(10 \mu \mathrm{g} / \mathrm{ml}, 25 \mu \mathrm{g} / \mathrm{ml}, 50 \mu \mathrm{g} / \mathrm{ml}, 100 \mu \mathrm{g} / \mathrm{ml}$ and $150 \mu \mathrm{g} / \mathrm{ml}$ ) for $24 \mathrm{hr}$. There is no significant difference on cell viability at concentration of $10 \mu \mathrm{g} / \mathrm{ml}$. The cell viability was reduced in a dose-dependent manner, in the cell lines and the significant cytotoxicity was observed from $25 \mu \mathrm{g} / \mathrm{ml}$ and above concentrations (Figure 6), for cell line which might be due to over-accumulation of metal nanoparticle inside the cell.

Metal nanoparticles can bring toxicity at various degrees. However, it is suggested that higher concentrations of AuNPs are toxic and can cause various health problems. AuNPs, however, possess moderate toxic activity against cell line. This might be due to small particle size of AuNPs with enormous specific surface area, which assisted further expression and ion dissolution thus, potentially leading to increased toxicity. Since these NPs are exhibit oxidative potential, reactive in nature and have ability to bind with proteins and DNA, resulting in generating the disturbance in the working of biomolecules [14].

The present study supported the notion as higher doses of gold nanoparticles exhibited the cytotoxicity on cell line used. These results direct towards the potential use of biologically synthesized gold nanoparticles as an anti-microbicide, occupying

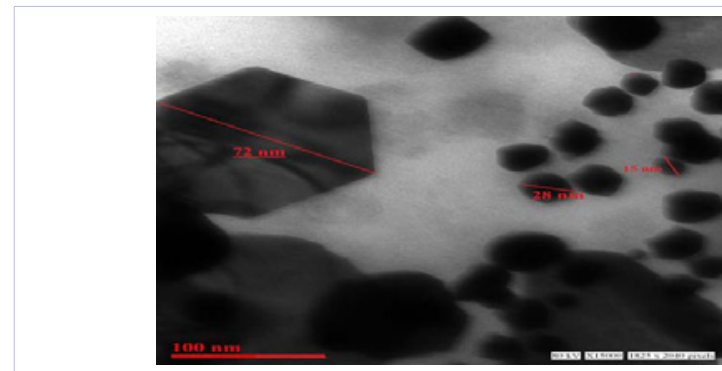

Figure 3: Transmission electron microscopic analysis of AuNPs

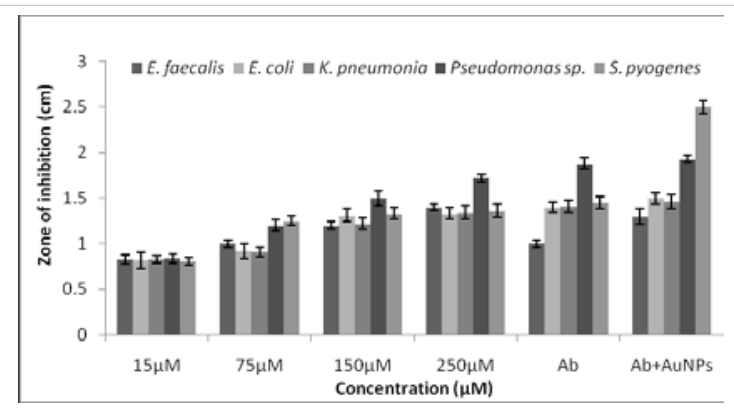

Figure 4: Comparative analysis of antibacterial activity AuNPs for different pathogenic bacteria. Results are presented in relative units compared with controls $(\mathrm{Ab})$. Data represent the mean \pm standard deviation of the mean of three individual experiments. $\mathrm{p}<0.05$.

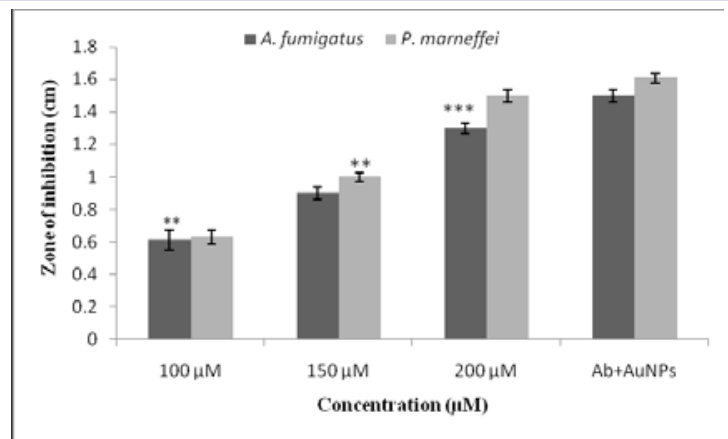

Figure 5: Comparative analysis of antifungal activity AuNPs for different pathogenic fungi. Results are presented in relative units compared with controls $(\mathrm{Ab})$. Data represent the mean \pm standard deviation of the mean of three individual experiments. $\mathrm{p}<0.05$.

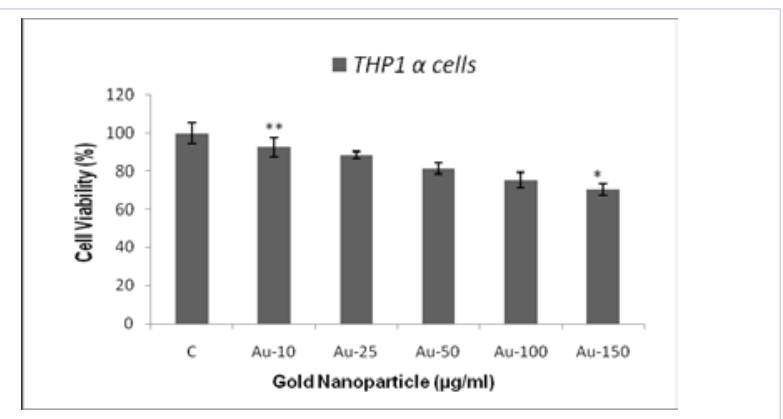

Figure 6: Dose-dependent effect of AuNPs over cell viability using MTT assay on THP1 $\alpha$ cell line. Results are presented in relative units compared with controls. Data represent the mean \pm standard deviation of the mean of three individual experiments. $\mathrm{p}<0.05$ 
its application in agriculture as well as in pharmaceutical area. Moreover, these AuNPs can also act as microbicidal agent alone or in combination with antibiotics.

\section{Conclusion}

In conclusion, a simple, stable and eco-friendly method of biosynthesizing AuNPs was successfully developed using $A$. brassicae fungus, identified it on the basis of morphological, biochemical and molecular techniques. This fungus produces extracellular, protein capped, water dispersible and highly stable gold nanoparticles, when reacted with aqueous solution of $\mathrm{HAuCl}_{4}$. Gold nanoparticles produced by $\mathrm{A}$. brassicae were in the size range of $15 \mathrm{~nm}$ to $72 \mathrm{~nm}$ and found to be spherical or hexagonal in shape and had irregular morphologies which were confirmed by SEM analysis. Furthermore, these functionalized AuNPs were more effective as antibacterial agents both against gram positive and gram negative bacteria. The AuNPs generated here also proved as a promising antimicrobial agent against both Gram-positive/Gram-negative bacteria and pathogenic fungi also. All AuNPs samples showed, good free radical scavenging activity. Finally, the AuNPs showed significant cytotoxicity against THP1 $\alpha$ (human macrophage cell lines). On the contrary, AuNPs, which were found to be nontoxic in cytotoxic assays, can be used as a vehicle for drug delivery. However, higher doses of gold nanoparticles exhibited the cytotoxicity on THP $1 \alpha$ cell lines. The fungal strain used in this study is likely to provide broad-spectrum benefits such as its efficacy in the solubilization of insoluble phosphate into soluble form, used to generation of AuNPs, its usefulness in the implementation of infectious diseases as drug delivery vehicle as well as in the area of agriculture (antibacterial and antifungal agent). Hence, these AuNPs can be considered as a carrier in targeted drug delivery system as well as enhancer for crop production which may lead to cheaper, non toxic and non-hazardous to the environment.

\section{Competing interests}

The authors declare that they have no competing interests

\section{Acknowledgements}

The authors are highly thankful to Vice Chancellor, Integral University for his support and encouragement. We sincerely thank Ms. Himani, IIT, Kanpur for carrying out SEM/TEM analysis of nanoparticles. The grant of UGC-Maulana Azad National Fellowship is gratefully acknowledged.

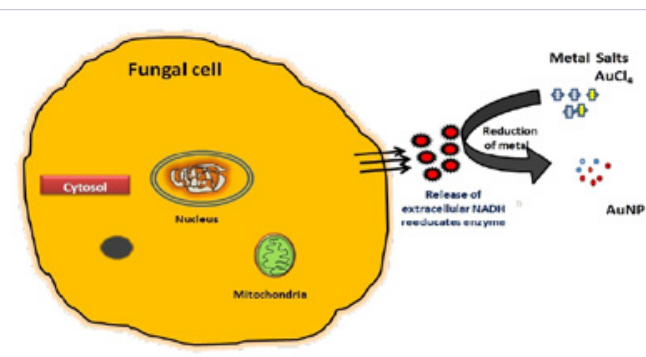

Figure S1: Schematic representation of reduction of metal ions by fungal secretary proteins

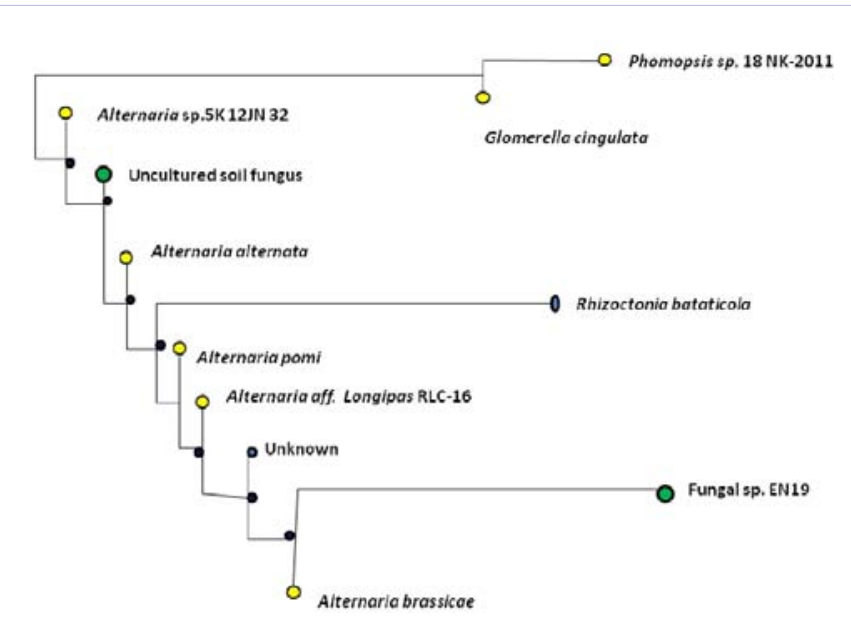

Figure S2: Phylogenetic analysis of A. brassicae (KF934409)

\section{References}

1. Ahmad A, Senapati S, Khan I, Kumar R, Sastry M. Extra-/intracellular biosynthesis of gold nanoparticles by an alkalotolerant fungus, Trichothecium sp. Biomed Nanotechnol. 2005;1(1):47-53.

2. Ahmad RS, Sara M, Shahverdi H, Jamalifar H, Nohi A. Rapid synthesis of silver nanoparticles using culture supernatants of Enterobacteria: A novel biological approach. Process Biochem. 2007;42(5):919-923.

3. Avinash I, Mahendra R, Aniket G, Manisha B. Fusarium solani: A novel biological agent for the extracellular synthesis of silver nanoparticles. J Nanopart Res. 2009;11:2079-2085. DOI: 10.1007/s11051-0089573-y.

4. Rashmi S, Preeti V. Biomimetic synthesis and characterization of protein capped silver nanoparticles. Biol Res Technol. 2009;100(1):501-504.

5. Boisselier E, Astruc D. Gold nanoparticles in nanomedicine: preparations, imaging, diagnostics, therapies and toxicity. Chem Soc Rev. 2009;38(6):1759-1782.

6. Zeinab S, Farzad K. Biological synthesis of gold nanoparticles by fungus Epicoccumnigrum. J Clus Sci. 2011;22(4):661-665.

7. Saha S, Sarkar I, Chattopadhyay D, S Patra, A Chakraborty. Production of silver nanoparticles by a phytopathogenic fungus Bipolaris nodulosa and its antimicrobial activity. Dig J Nanomater Biostruct. 2010;5(4):887-895.

8. Sarkar J, Ray S, Chattopadhyay D, Laskar A, Acharya K. Mycogenesis of gold nanoparticles using a phytopathogen Alternaria alternata. Bioproc Biosyst Eng. 2012;35(4):637-643. doi: 10.1007/s00449011-0646-4.

9. Thoomatti S, Peramchi P. Synthesis and structural characterization of polydisperse silver and multishaped gold nanoparticles using Fusarium oxysporum mtcc 284. Dig J Nanomater Bios. 2011;6(4):1587-1595.

10. Thangapandiyan S, Prema P. Chemically fabricated silver nanoparticles enhances the activity of antibiotics against selected human bacterial pathogens. Int J Pharm Sci Res. 2012;3(5):1415-1422.

11. Wright J, Lam K, Hansen D, Burrell R. Control: Efficacy of topical silver against fungal burn wound pathogens. Amc J Infest. 1999;27(4):344350.

12. Hussain S, Hess K, Gearhart J, Geiss K, Schlager J. In Vitro Toxicity 
of Nanoparticles in BRL 3A Rat Liver Cells. Toxicol In Vitro. 2005;19(7):975-983

13. Dorau B, Arango R, Green F. Forest Products Society: Proceedings of the $2^{\text {nd }}$ Wood-Frame Housing. Durabili and Disaster Issues Conference. 2004;133.

14. Reidy B, Haase A, Luch A, Dawson K. Mechanisms of silver nanoparticle release, transformation and toxicity: a critical review of current knowledge and recommendations for future studies and applications. Lynch Mat. 2103;6(6):2295-2350.

15. Pikovskaya I. Mobilization of Phosphate in Soil in Connection With Their Vital Activities of Some Microbial Species. Microbiol. 1948;17:362-370.

16. Garrity G, Springer V. Bergey's Manual of Systematic Bacteriology. In Bergey's Man Syst Bacteriol. 2001;742.

17. Dias L. Análises multidimensionais. A.C. Alfenas (Ed.), Eletroforese de Isoenzimas e Proteínas Afins. Fundamentos e Aplicações em Plantas e Microrganismos, UFV. Viçosa. 1998;405-473.

18. Germain V, Li J, Ingert Z, Pileni P. Satcking faults in formation of silver nanodisks. J Phys Chem B. 2003;107(34):8717-8720.

19. Perez C, Pauli M, Bazerque P. An antibiotic assay by agar-well diffusion method. Acta Biologiae et Med Exp. 1990;15:113-115.
20. Ndukwe J, Habila I, Adeleye E, Juss A. Phytochemical analysis and antimicrobial screening of crude extracts from the leaves stem bark and root bark of Ekebergia senegalensis. A. Afri J Biotech. 2006;5(19):1792-1794.

21. Mosmann T. Rapid calorimetric assay for cellular growth and survival: Application to proliferation and cytotoxicity assay. J Immunol Method. 1983;65(1-2):55-63.

22. James J, Lam C, Mc cluskey R. Pulmonary toxicity of single-wall carbon nanotubes in mice 7 and 90 days after intra-tracheal instillation. Tox Sci. 2004;77(1):126-134.

23. Chaudhary I, Fatima F, Verma SR, Pathak Neelam, Siddiqiui Z. Isolation and characterization of microbes with phosphate solubilizers and lignin degrading abilities. Biochem. Cell. Arch. 2011;11(2):299-305.

24. Ingale AG, Chaudhari AN. Biogenic Synthesis of Nanoparticles and Potential Applications: An Eco-Friendly Approach. J Nanomed Nanotechol. 2013;4:165.

25. Sheikhloo Z, Salouti M. Katiraee F. Biological synthesis of gold nanoparticles by fungus Epicoccum nigrum. J Clust Sci. 2011;22(4):661-665.

26. Shankar S S, Ahmad A, Pasrichaa R, and Sastry M. Bioreduction of chloroaurate ions by geranium leaves and its endophytic fungus yields gold nanoparticles of different shapes. J Mater Chem. 2003;13:1822-1826 